\title{
PESQUISA EM EDUCAÇÃO AMBIENTAL E QUESTÕES METODOLÓGICAS: UMA DISCUSSÃO COLETIVA ${ }^{1}$
}

\author{
Marília Freitas de Campos Tozoni-Reis ${ }^{2}$ \\ Daniele Cristina de Souza ${ }^{3}$
}

Resumo: Os Encontros de Pesquisa em Educação Ambiental - EPEAs - têm, em sua estrutura, os Grupos de Discussão de Pesquisa (GDPs). São sessões para discussão e aprofundamento de temas considerados significativos para a pesquisa em educação ambiental, mas que também devem ser consideradas um espaço de participação dos pesquisadores que apresentam trabalhos relacionados aos temas dos GDPs. O GDP Questões Metodológicas se reuniu no VII EPEA em 2013, empreendendo discussões acaloradas que resultaram na elaboração de alguns indicadores para a pesquisa em nosso campo garantir, cada vez mais, compromisso social e competência científica em seu processo de amadurecimento. Este artigo apresenta parte dessas discussões com ênfase nesses indicadores.

Palavras-chave: Metodologia de pesquisa. Epistemologia. Fenômeno educativo.

\section{RESEARCH IN ENVIRONMENTAL EDUCATION AND METHODOLOGICAL ISSUES: A COLLECTIVE DISCUSSION}

Abstract: The Research on Environmental Education Meetings (EPEAs, in Portuguese) include in their schedule the Groups on Research Discussion (GDPs, in Portuguese). These are sessions to discuss and deepen themes considered significant to the research on environmental education but that must also be seen as a moment to gather the participation of researchers who present works related to the GDPs' themes. The GDP on Methodological Questions happened during the VII EPEA in 2013 and conducted effusive discussions which resulted in the building of some indicators to be used in the research of our field in order to ensure more and more social commitment and scientific competence in the field's maturation process. This article presents part of these discussions with emphasis on those indicators.

Keywords: Research methodology. Epistemology. Educational phenomenon.

\footnotetext{
1 Este texto é, na realidade, de autoria de todos os membros do Grupo de Pesquisa em Educação Ambiental que funciona junto ao Programa de Pós-Graduação em Educação para a Ciência da FCUNESP-Bauru, que planejou e realizou os trabalhos do GDP Questões Metodológicas: Marilia Freitas de C. Tozoni-Reis, Jandira Líria B.Talamoni; Maria de Lourde Spazziani; Jorge Sobral da Silva Maia; Angélica Góis Morales; Regina Helena Munhoz; Lucas André Teixeira; Lílian Giacomini Cruz; Daniele Cristina de Souza; Eliane Aparecida Toledo Pinto; Marcela de Moraes Agudo; André Santachiara Fossaluza; Pâmela Figueiredo; Simone Franzi; Carolina Borghi Mendes.
}

\footnotetext{
2 Professora Doutora do Departamento de Educação do IB-UNESP-Botucatu e do Prrograma de PósGraduação em Educação para a Ciência da FC-UNESP-Bauru. Lider do Grupo de Pesquisa em Educação Ambiental - GPEA. mariliaedu@ibb.unesp.br

${ }^{3}$ Doutora em Educação para a Ciência da FC-UNESP-Bauru. Membro do Grupo de Pesquisa em Educação Ambiental - GPEA. danicatbio@yahoo.com.br
} 


\section{INVESTIGACIÓN EN EDUCACIÓN AMBIENTAL Y CUESTIONES METODOLÓGICAS: UNA DISCUSIÓN COLECTIVA}

Resumen: Las reuniones de Investigación en Educación Ambiental - EPEAs - tienen, en su estructura, los Grupos de Discusión de Investigación (GDIs). Las sesiones son para la discusión y se desarrollan cuestiones que son importantes para la investigación en educación ambiental, sino que también deben ser considerados como un espacio de interés de los investigadores que presentan trabajos relacionados con el GDI. El GDI Aspectos Metodológicos reunió en EPEA VII, en 2013, emprendiendo acaloradas discusiones que dieron lugar a la elaboración de indicadores para garantizar que la investigación en nuestro campo demuestre el compromiso social y la experiencia científica en el proceso de maduración. En este artículo se presenta parte de estas discusiones con énfasis en los indicadores.

Palabras clave: Metodología de la investigación. Epistemología. Fenómeno educativo.

\section{Introdução}

A Comissão Organizadora dos Encontros de Pesquisa em Educação Ambiental EPEAs - criou, em sua estrutura bianual, entre outras atividades, os Grupos de Discussão de Pesquisa (GDPs). São sessões para discussão e aprofundamento de temas considerados significativos para a pesquisa em educação ambiental, mas que também devem ser consideradas um espaço de participação dos pesquisadores que apresentam trabalhos relacionados aos temas nos EPEAs, um espaço de identificação das tendências e dificuldades da pesquisa em educação ambiental sobre esses temas relacionados. Os GDPs ocorrem durante dois encontros de duas horas de duração, incluídos na programação dos EPEAs, e são coordenados por pesquisadores convidados com experiência na temática desenvolvida. A orientação geral da Comissão é de que, a partir de uma análise prévia dos trabalhos apresentados no evento, o coordenador estimule um debate entre os participantes. Esses coordenadores têm acesso prévio aos trabalhos dos inscritos no Grupo de Discussão para identificar as relações possíveis entre eles, para que no momento de discussão coletiva possam contribuir na exploração das tendências e dificuldades percebidas. Posteriormente, um relato das reflexões do Grupo é socializado com todos os participantes do evento, durante uma mesa redonda que, em geral, antecede ao encerramento do Encontro.

A Comissão Organizadora, juntamente com os coordenadores de GDPs, vêm empreendendo esforços, desde a origem dos GDPs nos EPEAs, para que em cada Grupo a temática seja desenvolvida - tanto na apresentação quanto nas discussões enfatizando os trabalhos apresentados que, pela inscrição dos pesquisadores, foram vinculados a cada GDP. O objetivo é que os GDPs se constituam em um espaço produtivo para socialização, aprofundamento e ampliação das discussões sobre cada tema do GDP. Esse tem sido um dos principais desafios na organização dos EPEAs, pois essa articulação dos GDPs com os trabalhos de pesquisa apresentados no evento ainda não está plenamente compreendida pelo conjunto de participantes nos EPEAs, conforme pode-se observar nas escolhas até agora realizadas. A expectativa dos organizadores é que os pesquisadores se mantenham, na medida do possível, vinculados 
aos GDPs, para consolidá-los como um espaço permanente de discussões, acumulando conhecimentos sobre esses diferentes temas.

Desde o início da introdução dessa atividade nos EPEAs, alguns GDPs sofreram mudanças, alguns foram desarticulados, outros foram criados, e, atualmente, como observou-se no VII EPEA, em 2013, temos oito GDPs em funcionamento: Pesquisa em EA e Movimentos Sociais; Pesquisa em EA e Contexto Escolar; Pesquisa em EA e Contextos não escolares; Pesquisa em EA e Questões Epistemológicas; Pesquisa em EA e Formação de Professores/Educadores; Pesquisa em EA e Políticas Públicas; Pesquisa em Educação Ambiental e Culturas; e Pesquisa em EA e Questões Metodológicas.

Este artigo relata a organização e o funcionamento do Grupo de Discussão de Pesquisa em EA e Questões Metodológicas no VII EPEA, em 2013.

\section{Preocupações Iniciais: a metodologia de pesquisa nos trabalhos dos EPEAs}

Partindo da compreensão de que, pela sua natureza e importância, os EPEAs têm se consolidado como um espaço privilegiado de discussão da pesquisa em educação ambiental, assumimos, junto à Comissão Organizadora, a coordenação do GDP de Pesquisa em EA e Questões Metodológicas. Compreendemos, desde o primeiro momento, que esse deveria ser um compromisso coletivo, do Grupo de Pesquisa em Educação Ambiental - GPEA - que funciona junto ao Programa de Pós-Graduação em Educação para a Ciência da UNESP de Bauru, que assumiu coletiva e prontamente o compromisso.

Assim, iniciamos o trabalho coletivo de organização do GDP ainda no final do ano de 2012. Nossa primeira preocupação foi realizar um levantamento sobre o tratamento dado às questões metodológicas nos trabalhos de pesquisa em educação ambiental apresentados em todas as seis edições anteriores do EPEA (2001, 2003, 2005, 2007, 2009 e 2011). Assim, dividimos os trabalhos publicados nos Anais por membros do Grupo, individualmente ou em duplas, e criamos algumas categorias de análise que nos interessava para avaliar. Tínhamos expectativas de que teríamos muito a analisar, pois o EPEA é um espaço científico dedicado especificamente à discussão da Pesquisa em Educação Ambiental, atividade em que as questões metodológicas são intrínsecas e fundamentais.

Esses resultados, quantitativos e qualitativos, foram apresentados nos encontros do GDP no VII EPEA e orientaram as discussões. Num total de 481 trabalhos de pesquisa analisados, apresentados nas seis edições anteriores a 2013 nos EPEAs, identificamos 352 trabalhos com relatos de pesquisas concluídas, 118 ensaios teóricos e 11 trabalhos de pesquisas em andamento. Os membros do Grupo de Pesquisa dividiram entre si a leitura de todos esses trabalhos, particularmente o resumo e o item dedicado à Metodologia da pesquisa apresentada, quando explicitado no texto. Quando não encontramos esse item, todo o texto foi examinado para que pudéssemos encontrar a metodologia da pesquisa apresentada. Como era de se esperar, a maioria dos trabalhos de todos os EPEAs examinados anunciou a metodologia de pesquisa empregada (339), numa seção própria ou em outra, mas ainda foram identificados trabalhos que não a anunciaram (74) ou que tratavam dessas questões de forma tão confusa ao ponto de não conseguirmos concluir essa análise (68), como demonstra a Tabela 1, referindo-se a esses dados em cada uma das edições do evento. 
Tabela 1 - Anunciam metodologia

\begin{tabular}{|c|c|c|}
\hline & SIM & NÃO \\
\hline I (2001) & 45 & 35 \\
\hline II (2003) & 53 & 2 \\
\hline III (2005) & 46 & 0 \\
\hline IV (2007) & 64 & 24 \\
\hline V (2009) & 72 & 10 \\
\hline VI (2011) & 59 & 3 \\
\hline confusos & \multicolumn{2}{|c|}{68} \\
\hline TOTAL & 339 & 74 \\
\hline
\end{tabular}

Outra preocupação do Grupo que trabalhou nesse levantamento, de caráter mais qualitativo, foi a abordagem científica dada à Metodologia de Pesquisa expressa nos trabalhos apresentados. Sabemos que a pesquisa em educação ambiental é prática científica à qual se dedicam pesquisadores de diferentes formações e, por isso, diferentes concepções e experiências de pesquisa. Talvez essa seja a principal explicação para que as abordagens dadas à Metodologia de Pesquisa expressa nos trabalhos sejam tão diferentes como as que constatamos. Agrupamos essas diferentes abordagens em dois grandes grupos: técnica (descritiva) e teórico-técnica (descritiva e analítica), conforme apresentadas na Tabela 2. Isto é, constatamos que a maioria (207) dos 339 trabalhos que anunciam a Metodologia empregada, o fazem de forma essencialmente técnica, descritiva, muitas vezes reduzindo as questões metodológicas aos procedimentos técnicos de pesquisa. Os outros 132 trabalhos relacionavam de alguma forma os procedimentos de pesquisa às questões mais amplas do processo de investigação, conferindo às questões metodológicas uma maior complexidade, apresentando-as, também, de forma reflexiva e analítica. É interessante, ainda, observarmos que não há, dentre a distribuição dessa análise entre as diferentes edições do EPEA, uma tendência progressiva entre os dois grupos de abordagens metodológicas dos trabalhos apresentados, pois, embora a maioria dê uma abordagem técnica, de forma geral, em uma das edições (2005) essa tendência se inverteu.

Tabela 2 - Tipo de abordagem

\begin{tabular}{lcc}
\hline & Técnica & Técnica/Teórica \\
\hline I (2001) & 30 & 16 \\
II (2003) & 37 & 15 \\
III (2005) & 16 & 29 \\
IV (2007) & 44 & 25 \\
V (2009) & 45 & 27 \\
VI (2011) & 35 & 20 \\
& $\mathbf{2 0 7}$ & $\mathbf{1 3 2}$ \\
\hline TOTAL & & $\mathbf{3 3 9}$ \\
\hline
\end{tabular}

Outro dado interessante é que, mesmo que as diferenças de formação e atuação dos pesquisadores resultem na pesquisa compreendida de diferentes formas, prevalecendo sua descrição mais técnica, uma tendência predominou na explicitação das questões metodológicas em nossas análises: a abordagem qualitativa de pesquisa. A educação ambiental, como uma área híbrida, ora se relaciona mais diretamente às referências teóricas e metodológicas das ciências exatas e biológicas - com os 
paradigmas hegemônicos da ciência clássica, tradicional, moderna - e ora se relaciona mais diretamente com as referências teóricas da educação, com os paradigmas hegemônicos das ciências humanas. No entanto, é muito significativo observarmos que, embora a descrição mais técnica das questões metodológicas seja predominante nos trabalhos analisados, a explicitação da metodologia de pesquisa qualitativa também é predominante.

O Grupo que coordenou o GDP de Pesquisa em educação ambiental e questões metodológicas no VII EPEA compreende a metodologia de pesquisa mais relacionada à concepção de ciência, uma compreensão que se aproxima daquela hegemônica na área da pesquisa em educação: concebida como parte da grande área das ciências humanas. Isso significa que nossas referências nos levam a compreender a pesquisa como uma ação de conhecimento da realidade em sua abordagem interpretativa, isto é, a pesquisa como um processo de investigação, minucioso e sistematizado, para conhecermos a realidade socioambiental, refletida qualitativamente. O mais importante para nós, nessa perspectiva, é compreender a pesquisa como um processo de produção de conhecimentos para a compreensão de uma dada realidade educativa ambiental a partir do que nos ensina Minayo (2002, p.17):

\footnotetext{
Entendemos por pesquisa a atividade básica da Ciência na sua indagação e construção da realidade. É a pesquisa que alimenta a atividade de ensino e a atualiza frente à realidade do mundo. Portanto, embora seja uma prática teórica, a pesquisa vincula o pensamento e ação. Ou seja, nada pode ser intelectualmente um problema, se não tiver sido, em primeiro lugar, um problema da vida prática.
}

A Metodologia de Pesquisa, portanto, é o caminho percorrido pelos diferentes estudos para a interpretação da realidade educativa ambiental a ser desvelada. A pesquisa é, então, como afirma Santos (1989, p.13), "prática social de conhecimento", isto é, a produção de conhecimentos que se dá pela atividade de pesquisa tem uma dimensão social, seu objetivo último é a produção de conhecimentos para a organização da vida social. No entanto, sabemos que no mundo acadêmico convivemos com concepções de pesquisa que se relacionam mais diretamente com o método, com a sistematização dos conhecimentos, do que com seu objetivo principal, a interpretação da realidade - seja ela a realidade humana e social, biológica ou física.

Em qualquer abordagem metodológica, mais conceitual ou mais técnica e operacional, as explicações sobre a atividade de pesquisa vêm sempre associadas ao conhecimento, ou mais especificamente à produção de conhecimentos. Neste sentido, foi preciso refletirmos, o Grupo organizador, sobre a produção de conhecimentos abrigada na dimensão teórica e prática de compreensão do mundo, dos homens e das coisas, o conhecimento como um instrumento para o entendimento das relações dos sujeitos entre si e deles com o ambiente em que vivem, especificando-o nos processos educativos, isto é, na interpretação dos fenômenos educativos das relações humanas no ambiente.

Sem necessidade de consenso, os pesquisadores fazem escolhas teóricas, e o confronto de ideias e posições diferentes e divergentes, se tratadas de forma acadêmica, trazem crescimento e aprofundamento aos conhecimentos produzidos, contribuindo para a construção de um saber educativo ambiental onde a diversidade, assim como a complexidade, são características. Conscientes dessa diversidade e complexidade, os pesquisadores em educação ambiental produzem conhecimentos que vão se constituir no saber educativo ambiental, conhecimentos comprometidos com determinadas 
concepções de sociedade, educação e ambiente, mas voltados para o aprimoramento do processo educativo ambiental.

Com essas preocupações nos propusemos a levar ao GDP Pesquisa em Educação Ambiental e Questões Metodológicas, durante o VI EPEA em 2013, dados e discussões sobre os caminhos metodológicos para a pesquisa em educação ambiental, construídos a partir da ideia da diversidade e da complexidade. Nossa expectativa foi investir na construção coletiva de reflexões acerca das questões metodológicas da pesquisa em educação ambiental. No entanto, isso não significou conduzir os trabalhos de forma neutra. Assim, sem objetivos de neutralidade, nos posicionamos a favor de metodologias de pesquisa em educação ambiental comprometidas com um projeto de sociedade mais justa e igualitária - social e ambientalmente -, nossa compreensão de sociedade sustentável.

\section{As questões metodológicas da pesquisa em educação ambiental discutidas no GDP}

Durante o Encontro, o GDP iniciou seus trabalhos com a apresentação de todos os membros participantes do evento ali presentes. Essas apresentações tiveram o objetivo de proporcionar, a todos, possibilidades de conhecer um pouco mais os membros do GDP e, em particular, suas expectativas com relação às discussões sobre as questões metodológicas da pesquisa em educação ambiental. Como esperávamos, observamos grande diversidade de formação e de instituições de atuação dos pesquisadores em educação ambiental com predomínio da área de ciências biológicas. Durante as apresentações, pudemos observar, também, uma preocupação comum entre os participantes: aprofundar os aspectos em torno da metodologia de pesquisa em educação ambiental, pois muitos deles encontram-se no início do processo de migração de sua área de formação específica (ciências naturais e ciências exatas) para a da Educação Ambiental (ciências humanas e sociais). Também observamos que alguns desses participantes tinham já mais tempo nesse processo de migração.

Logo após as apresentações, esclarecemos, como coordenadores do GDP, o sentido e os objetivos desta atividade no EPEA, reafirmando que deveríamos levantar e discutir as questões metodológicas da pesquisa em EA, ou seja, nossas preocupações metodológicas como pesquisadores em educação ambiental, pois pudemos notar que, em algumas apresentações, elas foram confundidas com as questões metodológicas da ação educativa ambiental. Essa situação foi resultado, segundo entendemos, das diferenças com relação ao tempo, à maturidade dos pesquisadores presentes no encontro: alguns participantes eram pesquisadores iniciantes na área e também na atividade de pesquisa, embora outros fossem muito experientes. O importante é que todos eles trouxeram preocupações com as questões metodológicas, que foram debatidas pelo GDP.

Também apresentamos aos participantes do GDP o levantamento sobre os procedimentos metodológicos que o Grupo coordenador empreendeu sobre os trabalhos publicados nos Anais dos diferentes EPEAs. Essa apresentação teve como objetivo apenas estimular os participantes e dar início às discussões, delimitando um ponto de partida na discussão: as questões metodológicas da pesquisa em educação ambiental.

Alguns membros do GDP, mais experientes nos processos de pesquisa, contribuíram para identificar com mais clareza a finalidade da pesquisa em educação ambiental, na medida em que essa identificação ainda é confusa, pois muitos trabalhos ainda trazem a produção de conhecimentos da ecologia, ou áreas afins, como seu 
objetivo, e isso também foi sentido nesse encontro. Foram levantados argumentos para reforçar que a pesquisa em educação ambiental trata da produção de conhecimentos em educação ambiental, isto é sobre os processos educativos ambientais.

Nesse ponto a discussão foi bastante interessante, indo na direção de buscar respostas sobre que conhecimento é esse?. O debate entre os participantes confirmou o conhecimento em torno dos processos educativos ambientais como ponto fundamental da nossa atividade de pesquisa, como nosso objeto de estudo. Isto se apoia - e expressa - um importante pressuposto da pesquisa em educação ambiental: a educação ambiental é educação, é processo educativo que tematiza o ambiente, é processo educativo voltado para a formação dos sujeitos para - e com - sua relação com o ambiente. Sobre essa discussão, algumas observações sobre o fato de que, no processo de migração de uma área para outra, alguns pesquisadores secundarizam essa relação foi destacado. Lembremos que poucos trabalhos em educação ambiental problematizam essa relação da educação ambiental com a educação, revelando uma situação já muito conhecida no campo da educação ambiental, mas ainda muito presente, como vemos, também, no relato dos Trabalhos do GDP Questões Epistemológicas, já publicado:

\begin{abstract}
[...] outro tema, que mais uma vez ganhou destaque, foi o que diz respeito à forma justaposta com que aparece a relação entre a educação como prática social e a adjetivação ambiental. Os participantes enfatizaram as dificuldades que encontram em transitar para a prática docente desde os conhecimentos específicos de cada área de formação, pois embora se defenda, há muito tempo, a ideia que a EA é um campo interdisciplinar por excelência, essa perspectiva ainda se apresenta mais como promessa do que como realidade (TREIN; CAVALARI, 2014, p.125).
\end{abstract}

Um ponto muito interessante nessa discussão foi a consideração dos participantes sobre como esse GDP, especialmente dedicado às questões metodológicas da pesquisa em educação ambiental, precisa criar mecanismos para orientar os participantes do EPEA para que essa atividade esteja voltada para os elementos constituintes dos processos educativos ambientais, portanto, para a produção de conhecimentos em torno desse processo, considerando toda sua complexidade.

Como desdobramento da discussão, apareceu também no GDP a pesquisa em educação como ponto de partida para a pesquisa em educação ambiental, ou seja, é importante que a produção de conhecimentos sobre os processos educativos, já consolidada no Brasil, seja a referência para nossas questões metodológicas. È importante considerar, portanto, que a pesquisa em educação já é vigorosa e atuante, e que traz para a compreensão dos fenômenos educativos e educacionais grande contribuição. Assim, se na educação não podemos esperar consensos teóricos e metodológicos, porque a ciência é dinâmica e complexa, na educação ambiental menos ainda, pois além das concepções teóricas e metodológicas sobre os fenômenos educativos, temos, também, várias e diferentes concepções acerca do fenômeno ambiental.

Diante disso, o GDP considerou que a busca de um consenso com relação às questões metodológicas não é necessária nem desejada, mas somente tem sentido se for num plano de respeito à diversidade dos referenciais teóricos e metodológicos. Essa preocupação esteve presente nas expectativas dos participantes com relação às discussões no GDP quando, por exemplo, conversamos sobre a formação de professores como um tema recorrente em nossa prática de pesquisa. Mais do que uma orientação metodológica para isso, o que importa, segundo os participantes do GDP, é que as 
questões metodológicas e epistemológicas trazidas para os pesquisadores tenham coerência e consistência. E essas podem se beneficiar enormemente se dialogarem mais frequentemente com as pesquisas em formação de professores da área da educação, também muito desenvolvida no meio científico como nos indicava André et al. (1999) num estudo sobre $o$ estado da arte das pesquisas sobre o tema.

No interior dessa discussão, destacamos aquela que foi considerada a principal questão metodológica da pesquisa em educação ambiental: a produção de conhecimentos científicos dos processos educativos ambientais, isto é, a pesquisa em nosso campo com o objetivo principal de realizar as interpretações científicas das ações educativas/formativas ambientais, considerando toda a diversidade presente em torno desses processos.

Os participantes do GDP entenderam, também, que o levantamento apresentado pelo Grupo Coordenador mostrou uma pequena tendência de avanço nas questões metodológicas, embora ainda demonstrasse muitas fragilidades. Considerou que a abordagem metodológica predominantemente técnica, limitada à apresentação dos procedimentos de pesquisa desvinculados de um aprofundamento teórico é uma das mais importantes fragilidades a ser superada. Consideraram necessário, então, estudos que tragam, para a educação ambiental, esclarecimentos conceituais acerca da metodologia de pesquisa em educação. Ou seja, é preciso que os pesquisadores, já experientes e também os iniciantes, se dediquem a responder, seja nas orientações dos trabalhos ou nas reflexões durante os processos de pesquisa à questões como $O$ que é método?, O que é método de pesquisa?, O que são modalidades de pesquisa? ou $O$ que são técnicas de pesquisa? e $O$ que são técnicas de análise dos resultados? etc.

Igualmente, as discussões no GDP levaram a propostas de estratégias formativas para os pesquisadores em educação ambiental. Considerada uma área nova e diversificada pelos participantes do GDP, mesmo com predominância de pesquisadores da área de ciências biológicas, a educação ambiental já avançou muito no que diz respeito à superação dos paradigmas da ciência clássica. Mas, ainda há muito a ser superado, particularmente as barreiras formativas dos jovens pesquisadores. Como falta na formação inicial das áreas de ciências naturais uma inserção dessas questões epistemológicas, de integração de enfoques teóricos e metodológicos diferentes, e o currículo seja focado numa tradição tecnicista e desvinculada dos aspectos socioculturais, essas medidas dizem respeito à formação dos pesquisadores em educação ambiental nos cursos de graduação e de pós-graduação. Essa questão também foi sentida em outro GDP:

No nosso entendimento, isto é devido especialmente à formação no âmbito das licenciaturas, onde as questões da educação estão separadas das questões específicas de cada área. As pesquisas realizadas junto aos professores expressam suas dificuldades em incluir a temática ambiental no currículo escolar como parte do projeto político pedagógico das escolas onde atuam (TREIN; CAVALARI, 2014, p.125).

Outra questão metodológica importante, colocada e discutida, relaciona-se ao paradigma disciplinar ou mesmo de área de conhecimento, resultado da imposição de estrutura e modelos científicos de outras áreas para a educação ambiental. Isso precisa ser considerado na reflexão metodológica para reconhecimento da cientificidade da área. Assim, a predominância da abordagem técnica das questões metodológicas está sustentada em uma fragmentação entre a discussão metodológica e a discussão epistemológica. Podemos considerar tal questão como aquela que mais mobilizou as 
discussões durante as atividades do GDP. É de enorme importância a articulação das questões metodológicas da pesquisa em educação ambiental com as epistemológicas dessa prática. Ou seja, muito contribuiria para a superação da tendência em tratar a metodologia da pesquisa em educação ambiental de forma mais técnica, do que conceitual e reflexiva, a articulação dessas discussões com as de epistemologia da pesquisa em educação ambiental. Para isso, consideramos que é urgente e necessário a produção de estudos epistemológicos, por parte dos pesquisadores, que se dediquem também às questões metodológicas, assim como, do ponto de vista mais prático e operacional, articular, nos EPEAs, os GDPs de Questões Metodológicas e Questões Epistemológicas.

Se considerarmos que, do ponto de vista da produção de conhecimentos, a episteme é um atributo eminentemente qualitativo, ele precede, em ordem $\mathrm{e}$ importância, os aspectos metodológicos do processo científico, e para nós, na educação ambiental, além da discussão epistemológica da educação e da ciência, a epistemologia ambiental tem espaço:

\begin{abstract}
A epistemologia ambiental, mais do que um projeto com finalidade de apreender um objeto do conhecimento, é um trajeto para chegar a saber o que é o ambiente, esse estranho objeto de desejo de saber que emerge do campo de externalidades e de extermínio para o qual foi enviado, expulso do logocentrismo e do círculo de racionalidade das ciências. $\mathrm{O}$ ambiente não é a ecologia, mas a complexidade do mundo; é um saber sobre as formas de apropriação do mundo e da natureza através das relações de poder que se inscreveram nas formas dominantes do conhecimento. A partir daí, abre-se o caminho que seguimos para delinear, compreender, internalizar e finalmente dar seu lugar - seu nome próprio - à complexidade ambiental (LEFF, 2002, p.17).
\end{abstract}

Embora muito anunciada, a discussão epistemológica foi considerada, nas análises empreendidas no GDP, ainda incipiente na educação ambiental. Isso fica evidente ao constatarmos que um número significativo dos trabalhos de pesquisa, apresentados nos EPEAs, trazem metodologias centradas nas técnicas, desvinculadas do referencial teórico do estudo, poucas vezes explicitado. É preciso, portanto, ter maior clareza e preocupação sobre a importância da articulação das questões metodológicas com as teorias, os propósitos da pesquisa, os problemas de pesquisa, os procedimentos técnicos etc.

Vários trabalhos em educação ambiental assumem, muitas vezes superficialmente, é preciso considerar, as críticas à ciência moderna, em especial, à centralidade do ser humano - racional - nas relações com a natureza. Assumir essa posição não basta para garantir coerência e qualidade, rigor teórico e metodológico às nossas pesquisas. Sem uma articulação radical entre os aspectos epistemológicos e metodológicos da pesquisa, essa posição torna-se empobrecida, vazia de conteúdos. É preciso, segundo as discussões empreendidas no GDP, superar essa ambiguidade: ao assumir posições críticas aos paradigmas da ciência moderna, como entender os aspectos metodológicos de forma técnica e operacional?

É essa articulação dos aspectos epistemológicos e metodológicos que expressará, segundo o que foi discutido no GDP, rigor e relevância científica e social à pesquisa em educação ambiental. A noção do rigor científico mobilizou os participantes de forma bastante acalorada: durante as discussões, alertou-se para o risco de se aprisionar a investigação a um determinado paradigma, hegemônico no campo, por exemplo, o que pode fragilizar a discussão epistemológica e cessá-la antes de realizá-la. Assim, a 
sugestão dos participantes foi no sentido de trabalhar com um conceito mais amplo de rigor científico, contemplando as noções de suficiência, relevância, pertinência e outros.

Esse rigor também foi discutido na perspectiva da necessidade de reconhecimento da área no que diz respeito ao seu valor científico. Esse reconhecimento, segundo as análises empreendidas pelos participantes do GDP, é importante e precisa ser constantemente conquistado. Muitos problemas ainda existem para que esse reconhecimento no que diz respeito à educação ambiental, tanto pelos nossos próprios pares que, muitas vezes se orientam por paradigmas diferentes e não reconhecem o valor da diversidade, como por nós mesmos, que temos que nos responsabilizar por essa conquista, explicitando com clareza e coerência os caminhos e resultados das pesquisas. Com essas preocupações, indicamos, como GDP, aos pesquisadores em educação ambiental a urgente necessidade de aprofundamento epistemológico e metodológico nos nossos trabalhos de pesquisa.

Sabemos que os referenciais teóricos e metodológicos hegemônicos nas ciências humanas e sociais originam-se de discussões epistemológicas já consolidadas nessa área. No entanto, essa consolidação não pode significar cristalização, ou seja, não pode significar rigidez epistemológica. Trata-se de uma discussão permanente, que caracteriza um também permanente movimento que traz avanços significativos na produção de conhecimentos nas áreas que elas abrigam. Isso significa que as discussões epistemológicas tematizam novos desafios para as pesquisas científicas para a educação e, em nosso caso, para a educação ambiental. Isso exige que o pesquisador realize um exercício de identificação de pontos essenciais que permitam o diálogo entre perspectivas teóricas, no sentido de se fazer entender em relação aos outros.

Nesse contexto das discussões no GDP, foram levantadas algumas questões: Qual o parâmetro para o rigor científico na educação ambiental? Estamos querendo nos aproximar dos parâmetros das ciências naturais? Estamos querendo nos aproximar dos parâmetros das ciências humanas e sociais? Não teríamos que desenvolver parâmetros próprios? Essas questões podem ser norteadoras de debates que aprofundarão as relações entre as questões epistemológicas e as questões metodológicas da pesquisa em educação ambiental, sentidas como necessárias e fundamentais no GDP.

\section{Considerações Finais}

Com o objetivo de identificar as principais questões metodológicas no desenvolvimento da pesquisa em educação ambiental, os participantes do GDP Questões Metodológicas no VII EPEA, em 2013, consideraram a importância da problematização e aprofundamento de alguns pontos em particular:

- o problema de fundo: a importância e necessidade da articulação entre a epistemologia e a metodologia no trabalho científico;

- o objeto de estudo (com todas as ressalvas necessárias a esse termo) da pesquisa em nosso campo como o fenômeno educativo ambiental

- a interpretação do fenômeno educativo ambiental está articulada a um ponto de partida que está implicada em um posicionamento, não sendo neutro;

- a necessidade de compreensão dos elementos essenciais que envolvem a metodologia de pesquisa: teoria, método, técnica, modalidade de pesquisa;

- a necessidade do reconhecimento e o rigor científico visto de forma complexa;

- o campo da educação ambiental como privilegiado na quebra de paradigmas; 
- a necessidade de aproximação entre o campo da educação ambiental e área da educação;

- $\quad$ as condições de trabalho dos pesquisadores e a questão do poder científico;

- a relevância social da pesquisa em educação ambiental;

- a problematização da produção coletiva dos conhecimentos pelos Grupos de Pesquisa.

É importante destacar, ainda, que os participantes do GDP Questões Metodológicas ocuparam grande parte do tempo juntos para problematizar sobre a necessidade de rigor científico na Pesquisa em Educação Ambiental. Nesse sentido, podemos considerar como síntese da discussão principalmente as preocupações com:

- relação entre metodologia e epistemologia;

- coerência interna da pesquisa (o que se anuncia e o que se faz);

- integração dos referenciais teóricos e metodológicos na interpretação da realidade estudada;

- diferenciação entre rigor científico e padronização dos trabalhos científicos;

- necessidade da construção de outro pensamento, outra ciência (referindo-se a ciência clássica moderna);

- considerar as especificidades das ciências humanas e suas implicações na metodologia de pesquisa.

Assim, como consideração final a este relato, podemos concluir que os trabalhos realizados pelo GDP Questões Metodológicas durante o VII EPEA, em 2013, iniciaram uma potencialmente frutífera discussão para contribuir nos estudos e pesquisas em nosso campo, de forma a realizar a função maior da produção do conhecimento científico em nossas sociedades, que é contribuir para fazê-la mais justa e igualitária, ambiental e socialmente.

\section{Referências}

ANDRÉ, M; SIMÕES, R.H.S.; CARVALHO, J.M.; BRZEZINSKI, I. Estado da Arte da Formação de Professores no Brasil. Educação \& Sociedade, Campinas, ano XX, nº6, dez., p. 301-309, 1999

LEFF, E. Epistemologia Ambiental. 2ed. São Paulo: Cortez, 2002.

MINAYO, M.C. Pesquisa Social: teoria, método e criatividade. Petrópolis, Vozes, 2002.

TREIN, E; CAVALARI, R.M.F. Pesquisa em Educação Ambiental e Questões Epistemológicas: a permanência e a renovação. Revista Pesquisa em Educação Ambiental, Rio Claro, v.9, n.1, p.120-132, jan-jun 2014. Disponível em: <http://www.periodicos.rc.biblioteca.unesp.br/index.php/pesquisa/article/view/8862>. Acesso em: $20 / 06 / 2014$.

Artigo submetido em 30/04/2014

Artigo aprovado em 30/06/2014 